\title{
The slippery slope of exporting invasive species: the case of Himalayan tahr arriving in South America
}

\author{
Werner T. Flueck
}

Received: 29 May 2009/Accepted: 25 September 2009/Published online: 6 October 2009

(C) Springer Science+Business Media B.V. 2009

\begin{abstract}
Releasing alien mammals was considered positive in the past, but impacts were recognized as important already decades ago. Himalayan tahr were introduced to New Zealand (NZ), resulting in overt damage and continuous government control programs. Existing laws could not prevent NZ exports, and Argentina imports of tahr, although NZ authorities recommended against these imports. National and provincial legislation was possibly too complex, contradictory or incomplete to be enforced, or had loopholes such that tahr were imported to Argentina (2000, 2006). The estimated population in 2008 was 400-450 tahr. As even common travel routes are used to cross national borders in South America illegally with live ungulates, and enterprises importing tahr have been intercepted for illegally transporting wild ungulates previously, there are substantial risks that tahr might be released to new sites. As huge areas lack natural barriers, landscapes are very similar to NZ environments successfully invaded by tahr, and
\end{abstract}

W. T. Flueck $(\square)$

National Council for Scientific Research, C.C. 176, 8400

Bariloche, Argentina

e-mail: wtf@deerlab.org

W. T. Flueck

Institute of Natural Resources Analysis, Universidad

Atlantida Argentina, Mar del Plata, Argentina

W. T. Flueck

Swiss Tropical Institute, University Basel, Basel,

Switzerland eradication or control are unfeasible, the future of Himalayan tahr in South America now hinges solely on releases or escapes. Importantly, the 2006 import was to Andean foothills which is an ecological time bomb. Considering climates, history of invasiveness in $\mathrm{NZ}$, and low required propagule pressure, tahr could perform from $34^{\circ}-55^{\circ} \mathrm{S}$ along the Andes. NZ still has many illegal liberations, thus it would be more difficult to contain illegal liberations in Argentina. It calls for more leadership and better standards by exporting countries, especially if they had the chance to experience the consequences of having received the exotic species earlier.

Keywords Invasion - Hemitragus jemlahicus . Introduction · Argentina · Policy .

Alien · Exotic

\section{Introduction}

Much has been learned about the consequences of releasing alien mammals to new environments. The learning process was slow, Phonecians and Romans likely saw only positive sides to translocating fallow deer (Dama dama), and Acclimatization Societies were going strong until the early twentieth century. Releasing ungulates allowed production, including hunting, for economic benefits. Releases were also 
done without economic motives, sometimes to add to depauperate local fauna and improve sport hunting. Such motives resulted in releases of several ungulate species in southern Latin America starting in the early 1900s (Flueck and Smith-Flueck 1993). Interest in impacts from such releases began already 7-8 decades ago in New Zealand (NZ), with governmentsupported control efforts since 1923. Thereafter, as the economic cost became apparent, global research efforts and publications on invasive species increased exponentially (Kolar and Lodge 2001). Today awareness about impacts from invasive species is quite elevated, and exotic species have been recognized as a leading global threat to native biodiversity and ecosystem function (Pimentel et al. 2000; Sala et al. 2000; Olson 2006). Moreover, invasion biology is a formal discipline and institutions like the National Invasive Species Information Center (USA), the Global Invasive Species Programme, the IUCN Invasive Species Specialist Group, the Global Invasive Species Information Network, or the IABIN Invasives Information Network $\left(\mathrm{I}^{\circ} \mathrm{N}\right)$ were formed. Nonetheless, significant gaps remain in international regulations regarding invasive alien species (Simons and De Poorter 2009), and there remains room for improvements with regards to international trade, as shown here with recent translocations of highly invasive Himalayan tahr (Hemitragus jemlahicus) from NZ to Argentina.

\section{Background on tahr}

The tahr is a sexually dimorphic bovid in the subfamily Caprinae. They reach $100-170 \mathrm{~cm}$ in length, $65-100 \mathrm{~cm}$ in shoulder height, and 36$125 \mathrm{~kg}$ (and more) of body weight. Females reach sexual maturity at 1.5 years and males at 3-4 years (socially). Females have usually one kid which at 2 weeks of age can jump a $1 \mathrm{~m}$ fence. Wild tahr in NZ have reached 22 years of age (Tustin 1990).

This species originated in the Himalayas where they occur in forests, steep terrain and rocky parts of high mountains. Tahr inhabit temperate to sub-alpine forests, but also use alpine areas above treeline (Bhatnagar and Lovari 2008; Kittur et al. 2009). They are rather shy, alert and difficult to approach. When disturbed, they escape surefooted even in steep and rocky terrain. In winter they may migrate to lower elevations and at times remain in dense vegetation for protection from weather. Tahr are considered threatened in the Himalaya area (Forsyth and Tustin 2001), although IUCN considers them only near threatened (Bhatnagar and Lovari 2008). Uncontrolled hunting, deforestation and excessive livestock production have reduced and isolated tahr populations (Bhatnagar and Lovari 2008). However, tahr in NZ turned out to be a noxious invasive species due to their rapid expansion, effects on soils, vegetation, hydrology and native biodiversity (Caughley 1970a; Forsyth 1999; Forsyth et al. 2000; Tustin 1990; DoC 2009a). The 2008 IUCN Redlist does not mention tahr in Argentina although official introductions occurred in 2000 and 2006.

\section{Introduced tahr in New Zealand}

History

Tahr were introduced in 1904, and by 1975 they already occupied all preferred areas on the South Island, approximately $6,150 \mathrm{~km}^{2}$. The rate of expansion was between 0.64 and $3.84 \mathrm{~km}_{\text {year }}{ }^{-1}$ (Tustin 1990). The government then decided to control tahr and several campaigns reduced the invaded area to $4,950 \mathrm{~km}^{2}$.

\section{Habitat use}

Tahr occupy areas between 500 and 2,250 masl, and rocks or steep slopes are used as escape terrain (Hughey and Hickling 2006). Tahr like north exposures in winter as there is less snow, are found in areas with $1,500-7,500 \mathrm{~mm}$ year $^{-1}$ of precipitation, in open areas but also in closed forests (even exclusively; Forsyth and Tustin 2001). Environments used in NZ are ecologically and climatologically equivalent to native Himalayan ranges, but the use of different environments in NZ is more pronounced, which is due to intense agricultural use of several environments in the Himalayas (Tustin 1990). There is no evidence that tahr had to adapt to NZ environments, except to shift breeding by 6 months.

Behavior and diet

Tahr use many plants including herbs, grasses and woody species. They also select certain flowers and 
stems with seeds. In the evening they move to lower zones for foraging during the night, returning to higher elevations in the morning and remaining there during the day. Such daily movements covered up to $450 \mathrm{~m}$ of elevation (Tustin 1990). During the summer it is common that tahr use areas containing domestic livestock, as occurs commonly in the Himalayas (Kittur et al. 2009).

Population dynamics and invasiveness

During colonization by unhunted populations, males arrived first followed by females about 10 years later. After only 16 years, population densities reached 33 tahr $/ \mathrm{km}^{2}$ across the whole study areas, equivalent to about $825 \mathrm{~kg} / \mathrm{km}^{2}$ of biomass, which would be more than double if considering only the vegetated portion of the area (Tustin 1990). Subsequent government control programs reduced densities back to $2.2 \mathrm{tahr} /$ $\mathrm{km}^{2}$ by 1977 . Without control hunting or toxicants, tahr populations increased at 35\%/year and doubled every 2-3 years (Caughley 1970a; Tustin 1990). Releases of 6 or more tahr were always successful, whereas those with $<6$ animals had some failures (Forsyth and Tustin 2001). Tahr had significant negative effect on flora and fauna (Forsyth 1999; Forsyth et al. 2000; Tustin 1990).

Control and management

Once the government initiated a control program based on helicopter hunting, a single crew commonly would retrieve over 100 tahr/day during winter, the record being 174 animals. Between 1972 and 1975 densities of tahr were thus reduced throughout their distribution.

Public hunting is now promoted to maintain densities at low levels, but where not achieved, government operators will continue. As tahr can live in very steep and rocky areas, hunting on foot causes tahr to retrieve to areas less accessible to foot hunters. In addition, public hunters are foremost interested in males for their horns, and not in females which determine recruitment rates. Hunters in fact do not control the tahr population as they only killed 522 in 2005 and 911 in 2006, necessitating culls by the DoC of 2,498 and 2,120 animals, respectively, to keep numbers close to the maximum set in the tahr control plan (DoC 2009b). Consequently, the only way to control tahr is by helicopter (Forsyth and Tustin 2001; Sage 2001). Tahr even learnt to avoid helicopters, hiding in brushy areas during the day and coming out to feed at night. The yearly cost to control and maintain low tahr densities is about US\$ 300,000 and eradication would cost US\$ 20 millions. Although formerly considered a viable option, eradication of tahr is no longer possible as they now occur in many private properties where eradication cannot be enforced (Forsyth and Tustin 2001): it would have had to be done at an earlier stage. The current objective of control is to maintain about $10,000 \mathrm{tahr}$ within a permitted zone, instead of about 50,000 if there were no control program (DoC 2008, www.biodiversity.govt.nz).

The impact from high densities is known and considered unsustainable, but hunting reduces densities only to $4.5-6.8 \mathrm{tahr} / \mathrm{km}^{2}$, whereas the government specified $<2.5 \mathrm{tahr} / \mathrm{km}^{2}$ to contain the modification of vegetation within acceptable margins (Forsyth and Tustin 2001). The other motive for control is to prevent that the affected area increases in size, by eradicating all tahr occurring outside the permitted area.

Hunting interests regularly cause illegal translocations of tahr to new areas. For the last 2 incidences NZ estimated a cost of US\$300,000 to eradicate these groups, which was considered necessary as they were outside of the permitted zone (Fraser et al. 2000). Also, captive herds are only permitted within the legal tahr zone.

\section{Introduced tahr in Argentina}

\section{Past history}

Petrides (1975) mentioned tahr in Argentina without specifying locality nor source. Later, tahr were said to be introduced to Neuquen province (Chebez 1994; Ubeda and Grigera 1995), and even specifically to Parque Diana ranch (Richard and Julia 2004). However, a detailed book about that ranch did not mention tahr (Vogel 1969), and the administrator, working there since 1970, never witnessed introductions of tahr (B. Affolter, personal communication). Thus, the supposed tahr introductions to Neuquen cannot be verified for any ranch with history of introducing exotic ungulates (unpublished data). I assume that the 
first mention of tahr in Argentina by Petrides (1975) was the basis for subsequent mentions (Chebez 1994; Ubeda and Grigera 1995; Richard and Julia 2004).

Currently, tahr in Argentina are only listed in the System of Biodiversity Information of National Parks (citing Ubeda and Grigera 1995), and by the National Secretariate of Mining (2008), both referring to introductions to Neuquen. Nationally, tahr are not listed (DNF: Dirección Nacional de Fauna, www.ambiente.gov.ar, 2009), nor listed in databases of the Invasives Information Network ( $13^{\circ} \mathrm{N}$-Argentina, IABIN; 2009), and not mentioned in recent books about exotic mammals in Argentina (Cabal 1988; Bonino 2005).

\section{Recent introductions}

Although tahr are absent in authoritative Argentine databases (DNF, IABIN, 2 books) or IUCN redlist (Bhatnagar and Lovari 2008), recent introductions to Argentina are certain events. Interest in importing tahr stemmed from the private sector and the source were suppliers from NZ, where tahr not only exist in the wild, but also in private breeding stations with the purpose to provide hunting opportunities and sale of live animals.

The exporter: New Zealand

The CITES convention does not apply to tahr in NZ. Furthermore, the government does not have a special provision to control export of its pest species. It recognizes that its adhesion to the international Convention on Biological Diversity (CBD) is at times in contradiction to its legislation on pest species like tahr (also see Simons and De Poorter 2009; Nunez and Pauchard 2009). In practice, a private person exporting tahr from NZ thus only has to be registered with the government and observe regulations regarding animal welfare.

When Argentine authorities supported tahr imports, their system did require certain documentation from NZ, like health certificates. Lacking tools to stop exporting tahr, the Department of Conservation (DoC) first contacted SENASA (Argentine National Service of Agrifood Health and Quality), stating that DoC is preoccupied if Argentine authorities understand the risks involved; that several public sectors in NZ are concerned that exporting tahr can result in environmental problems in Argentina; that DoC cannot prevent these exports; and that knowing now what tahr did to NZ, DoC would not permit introductions of tahr to NZ today. Furthermore, the letter underlined that keeping tahr in captivity requires sophisticated fencing as tahr are capable to climb and pass the type of fencing used to contain deer. Irrespectively, DoC had to sign the export permit for 5 males and 15 females to be flown to Argentina (2000).

\section{The importer: Argentina}

Di Paola and Kravetz (2004) described severe debilities of the Argentine legal system regarding invasive species, due to divisions into federal and provincial powers, contradicting legislation, and under-funded staff, control and enforcement.

National law 22.421 appears to have been applicable and should have prevented tahr imports. For instance, importations shall always be denied for species not listed in CITES I, but protected by law in the entire region of their natural habitat. The law also denies importation of live specimens of harmful or detrimental species. Both criteria seem applicable to tahr imports.

Importation of exotic fauna also requires intervention by National Fauna authorities with a specific environmental impact assessment process. An economic impact assessment must address: potential impacts from losses or changes in biodiversity, economic and productive risks, sanitation risks, and potential as pests. Impacts should be classified according to magnitude, duration or persistence, sign, and reversibility. Assessments must also cover impact prevention, mitigation and neutralization measures that must, at least, foresee the following: safety measures, sanitation measures, and harm mitigation measures. Moreover, assessments must include an environmental vigilance plan designed to guarantee the fulfilment of corrective measures. The responsible importer has to propose and finance a regular monitoring plan for early detection of accidental escapes. Lastly, assessments must provide a contingency plan that takes into account possible faults in the impact prediction process. National Fauna authorities would then form an ad-hoc Assessing Committee to review and revise the study. This committee of five prestigious members 
with expertise in the particular species would then present an environmental impact statement to the authorities.

The Secretariat of Environment and Sustainable Development (SAyDS) of Argentina though is, ultimately, the designated Enforcement Authority of the CBD. Although Article 8(h) of the CBD states that signatories should prevent introductions of those alien species which threaten ecosystems, habitats or species, and control or eradicate them, SAyDS determines specifically which organisms fit the category of "invasive species" (Di Paola and Kravetz 2004). Moreover, in 1997 SAyDS established that introductions of any new exotic species must be preceded by an environmental impact evaluation based on studies (Resolution 376). In 2003, a National Strategy on Biological Diversity (NSBD) was adopted, specifying that the Precautionary Principle be the basis for all future policy and regulations regarding imports or introductions of exotic species (Resolution 91, Boletín Oficial, 24/02/03). This would require banning introductions of all exotic species, unless a competent authority authorizes importation, and penalties and fines would apply in cases of illegal introductions. Again the NSBD requires environmental impact assessments which must be undertaken previous to introductions of exotic species; and that in cases of deliberate introduction of species for investigation, production, or other use, the assessment of socio-economic aspects should also be included in the environmental impact study, especially since failures may lead to releases of exotics. To prevent socio-economic burdens, the NSBD establishes that the legislation should require that the interested party provide financial support to guarantee escape control and to cover damages to third parties in the event of releases and to cover costs of restitution. Obviously, the objective of environmental assessments is to minimize risks and to determine responsibilities in case of problems, and to prevent that the situation converts to externalities at the cost of society (Perrings et al. 2005). However, although given these appropriate intentions (Simons and De Poorter 2009), the Secretariate declared in 2003 (SAyDS Boletín Oficial, 24/02/03) that "up to this date, there had been no authorizations given for the introduction of any new species of exotic fauna". Tahr thus slipped by these barriers in 2000 and entered in another way, and again in 2006.
So what caused Argentina to ignore the warning letter by DoC and extensive literature about impacts from tahr, to consider that law 22.421 was inapplicable, and not requiring prior environmental studies nor impact assessments? Maybe the constellation of the legal framework was still too disorganized in 2000 regarding invasive species (Di Paola and Kravetz 2004). But the second tahr introduction from NZ seems to point to major loopholes which makes Argentina an unfortunate source for alien species. Due to this most easy tahr importation in 2000, along with open propaganda on hunting tahr in Argentina, it is no surprise that it resulted in another $30 \mathrm{tahr}$ being flown to Argentina in 2006.

The tahr importation of 2000 was presented during the 2006 Argentine-Chilean meeting on huemul (Hippocamelus bisulcus), in presence of directors of National and Provincial Fauna departments; representatives of INTA, National Parks, and NGOs; chair of the IUCN Deer Specialist Group; and various representatives from Chilean institutions. Yet most notable is the fact that those groups in Argentina with expressed interest in alien species have not noted the ongoing tahr introduction to Argentina so far, even with many inescapable documentations (SENASA; airport authorities; authorities for inter-provincial transport of live hoof stock; several web sources offering hunting of tahr in Argentina; Flueck and Smith-Flueck 2006a, b, 2007; Jiménez et al. 2008).

The actual population of tahr in Argentina

I assume that females coming from NZ breeders in August 2000 were pregnant. Buyers commonly seek to buy pregnant females: the Argentine importer by principle sells guaranteed pregnant wild ungulates. Assuming a sex ratio at birth of $1: 1$, primiparity at 2 years, and an average success rate for a breeding station, the population would have consisted of 41 males, 52 females and 30 kids by 12/2004. These estimates are realistic and explain the first offer to hunt specimens in 2004. By 12/2008 it would be possible that 335 individual existed, and maybe less if some hunting was allowed. It is also highly likely that assisted reproductive technology was used to increase recruitment rates, in which case the total number would be larger.

The second importation in July 2006 certainly consisted of at least 20-25 pregnant females with a 
half a dozen males, and by 12/2008 there could have been some 113 tahr. In Argentina there would have thus been between 400 and 450 tahr by the end of 2008.

Factors in Argentina which potentiate the impact from ungulate introductions

Regarding movements of live animals, border control in South America is often wanting. First, the extensions of borders are huge and thus permeable. Second, even major traffic routes exhibit much flexibility due to human factors. Thus, the most convenient travel route, made for common vehicles and having maximal control, could not prevent that live red deer (Cervus elaphus) crossed the border illegally between Chile and Argentina (Flueck and Smith-Flueck 1993).

Although controls are wanting and an unknown percentage of illegal transports are being discovered, the enterprises involved with tahr imports (2000, 2006) have both been intercepted by authorities for illegally transporting wild ungulates (SENASA, press release 16/8/05). In one case, animals were hidden behind construction materials, and the driver assured that he did not know what he was transporting. In the other case, the enterprise tried to cross a precarious off-road bridges with some 25 wild deer in a truck. Also, the 2006 import resulted in a tahr population near the Andes, and in 2008 a federal indictment was issued based on wildlife laws, the case being pending.

Potential impacts from tahr in southern Latin America

Simons and De Poorter (2009) outlined risk assessments to be done before importing invasive species, recommending climate-matching, analysis of history of invasiveness and required propagule pressure, and other trait-based considerations. Judged by these criteria, establishment of tahr in the Andes following escapes or releases is very probable. Based on habitat use in the Himalayas and NZ, tahr likely can make use of all elevations found in foothills and high elevations of the southern Andes, including all habitat types (Forsyth and Tustin 2001; Hughey and Hickling 2006; Bhatnagar and Lovari 2008; Kittur et al. 2009). The herds brought to Argentina since 2000 have used their new environments successfully enough to allow regular hunting programs. Assuming similar population responses as had occurred in NZ, tahr liberated in the southern Andes likely would impact the flora, its associated fauna, soils and hydrology. The impact would extend beyond the one experienced in NZ which had no native land mammals (except bats). In the southern Andes, tahr would likely impact native camelids and cervids like the endangered huemul which now generally survives only in remote high elevation refuges, and in Argentina likely already number less than the current tahr population (Flueck and Smith-Flueck 2006a).

\section{Discussion}

Establishment of harmful invasive species requires several stages. It is a cascading event, starting with (1) importation, followed by (2) release or escape, (3) population establishment, (4) spreading, and (5) becoming a problem (Williamson 2006). The factors important at each stage can be different, with socioeconomic and legal factors being generally important initially, biogeographical, ecological and evolutionary later, but all can affect any stages. Tahr are on a slippery slope in Argentina and for that matter, South America. The first stage is already history and the estimated several hundred animals fully assure that the cascade could continue. Based on criteria suggested by Simons and De Poorter (2009), tahr could easily become established in the Andes. Stages 3, 4 and 5 are thus also assured since huge areas lack any natural barriers, southern Andean landscapes are very similar to environments successfully invaded by tahr in NZ, and the economical situation would not allow eradication nor control, as evidenced by the ongoing invasion by red deer (Flueck et al. 2003). Thus, the future of tahr in South America hinges on stage 2: releases or escapes.

Releases or escapes of tahr already present in Argentina are quite possible. First, their arrival involved numerous different authorities (aerial and land transports, crossing of international and interprovincial borders, etc.), tahr existed in Argentina since 2000, and there had been open advertisements on hunting opportunities. Yet all this did not result in pertinent institutions being aware of the presence of tahr: even accessible sources like Lastra (national newspaper La Nación), Flueck and Smith-Flueck 
(2006a, b, 2007) have gone unnoticed, and thus further movements might also go undetected. Second, hunting is being offered in new provinces, indicating possibly uncontrolled interprovincial traffic of live tahr. Third, to my knowledge, none of the properties with tahr has modified fencing which was constructed to contain mainly cervids within thousands of hectares. Fourth, uncontrolled interprovincial traffic and even across national borders has been documented. Lastly, the enterprises accomplishing twice to fly tahr into the country, have also been intercepted when attempting to illegally cross provincial borders with wild species. Although initially tahr are likely raised in large semi-natural hunting enclosures, each new enclosure is another potential source for escapes. Moreover, past and recent intentional releases of other game species, particularly cervids (Flueck and Smith-Flueck 1993; Flueck et al. 2003), to additional open areas supports a similar fate for tahr.

Simons and De Poorter (2009) proposed crucial steps a country should take before importing an invasive species. If risk assessments were done before importing tahr to Argentina (2000, 2006), these were not transparent and thus would lack recommended qualities (science-based, comparable and repeatable, based on reliable data, conducted using the best information available, considering uncertainties explicitly). Moreover, for risk assessments to be effective, they need to take into account the progression of a biological invasion from importation to release (or escape) into the environment, establishment, spread and impact. Attempts to flying in 20, and later another 30 Himalayan tahr to Argentina would seem to present opportunities for control and application of pertinent legislation. Yet these imports were successful which indicates that the legal system is inadequate (Di Paola and Kravetz 2004). In 2003, the National Strategy on Biological Diversity assured that no new exotic species had been admitted: this makes the tahr import of 2,000 an outlier. For any post-2003 events, the Precautionary Principle was to be applied, but tahr entered Argentina again in 2006, maybe because the earlier import served as a precedence. Overall it indicates that Argentina is very vulnerable to imports of new species.

Nunez and Pauchard (2009) suggested that developed countries could take the first step by no longer exporting invasive species to countries that cannot afford to fund research to properly assess the situation. Countries exporting noxious species could at least increase their standard of export conditions, aimed at reducing risks to recipient countries, by requesting and evaluating standardized information like impact assessments from recipient authorities, and more details on the importers. For instance, the export of 30 tahr in 2006 required the NZ exporter to guarantee that these be delivered to a specified address. Yet the provided absurd nonsense address identified only Argentina, and more importantly, it obscured the destiny which was the foothill country of the Andes (approximately $40^{\circ} 30^{\prime} \mathrm{S}, 71^{\circ} \mathrm{W}$ ), which is an ecological time bomb.

\section{The future of tahr in Argentina}

Certainly the worst scenario will be tahr released or escaping in the Andes. Compared to NZ environments, good habitat exist along the Andes from about $34^{\circ} \mathrm{S}$ to $55^{\circ} \mathrm{S}$. The topography, hydrology, climate and remoteness are very similar, many plant genera are shared, and this similitude to NZ is greater than NZ versus Himalayas (Godley 1960; Tustin 1990; Ezcurra et al. 2008). Furthermore, livestock use the same habitats in the Himalayas as tahr (Kittur et al. 2009), indicating that areas apt for livestock in the Andes likely are suitable for tahr. For these reasons, tahr likely would disperse rapidly and invade remote areas which would prevent any control measures. Remoteness, low human density and lack of large predators have allowed exotic red deer and boar to spread rapidly through the southern Andes (Flueck et al. 2003) which further supports the same scenario for tahr. Population development, impacts, and necessary investments in research and control measures of tahr in NZ give us the most realistic scenario about the consequences of tahr liberated in the Andean region (Christie and Andrews 1964; Caughley 1970a, b; Tustin 1990; Forsyth and Tustin 2001). In addition, I would suspect that tahr would also do well in the high Andes between $3^{\circ} \mathrm{S}$ and $25^{\circ} \mathrm{S}$, based on the ungulate fauna in that area.

Tahr in enclosures with no risks of escapes may be acceptable. There might also be cases where surrounding areas serve as efficient barriers which would not allow further dispersal. Yet even in NZ, considered a leading nation in the management of invasive species, a review of 11 ungulate species showed an 
increase in their distribution since the last survey (Fraser et al. 2000). Newly established populations were shown to originate as follows: for each 100 cases of escapes from farms, there were 68 illegal liberations and 13 due to natural dispersal. In one case of a new population, the analysis of its eradication showed the following (Fraser et al. 2003): it took 4,540 man hours (43\% to find the animals, $42 \%$ for control), and it cost NZ\$102,000 (without counting salaries nor general expenses) to eliminate 155 deer.

Aside of the risk from escapes, planned but illegal translocations with the goal to introduce tahr to new zones are more problematic. In NZ there were 258 new populations established, principally from escapes and illegal liberations (Fraser et al. 2000), and it would be appreciably more difficult to contain illegal liberations in Argentina with its large territories. As state borders among South American countries are large and permeable, even a better control on main airports and harbors is not a guarantee, as long as neighboring countries would still provide easy entrance for alien species. These circumstances call for more leadership and better standards by exporting countries, especially if they had the chance to experience the consequences of having received the exotic species earlier.

Acknowledgments I thank for helpful comments from anonymous referees which substantially improved the paper. I also thank several colleagues from New Zealand who made me aware of the situation and provided pertinent information. The work would not have been possible without the generous support from El Retorno, Bariloche and Cyon $\mathrm{GmbH}$, Switzerland.

\section{References}

Bhatnagar YV, Lovari S (2008) Hemitragus jemlahicus. In: 2008 IUCN Red List of Threatened Species. Available via http://www.iucnredlist.org. Accessed 30 May 2009

Bonino NA (2005) Guia de mamíferos de la Patagonia Argentina. Ediciones INTA, Buenos Aires

Cabal GB (1988) Animales exóticos. Fauna Argentina. Centro Editor de America Latina S.A, Buenos Aires

Caughley G (1970a) Eruption of ungulate populations, with emphasis on Himalayan thar in New Zealand. Ecology 51:53-72

Caughley G (1970b) Liberation, dispersal, and distribution of Himalayan thar (Hemitragus jemlahicus) in New Zealand. NZ J Sci 13:220-239

Chebez JC (1994) Los que se van. Editorial Albatros, Buenos Aires
Christie AH, Andrews JR (1964) Introduced ungulates in New Zealand: (a) Himalayan Tahr. Tuatara 12:69-77

Di Paola ME, Kravetz DG (2004) Invasive alien species: legal and institutional framework in Argentina. In: Miller ML, Fabian RN (eds) Harmful invasive species; legal responses. Environmental Law Institute, Washington DC, pp 71-88

DoC (2009a) Department of conservation: the threat of tahr. http://www.doc.govt.nz, downloaded 27 Aug 2009

DoC (2009b) Department of conservation: deer, chamois, tahr and pigs. http://www.doc.govt.nz, downloaded 27 Aug 2009

Ezcurra C, Baccala N, Wardle P (2008) Floristic relationships among vegetation types of New Zealand and the Southern Andes: similarities and biogeographic implications. Ann Bot 101:1401-1412

Flueck WT, Smith-Flueck JM (1993) Über das in Argentinien angesiedelte Rotwild (Cervus elaphus, L., 1758): Verbreitung und Tendenzen. Zeits Jagdwiss 39:153-160

Flueck WT, Smith-Flueck JM (2006a) Predicaments of endangered huemul deer, Hippocamelus bisulcus, in Argentina: a review. E J Wildl Res 52:69-80

Flueck WT, Smith-Flueck JM (2006b) Herbívoros exóticos y su papel en la recuperación del huemul. In: Administración de Parques Nacionales (ed) 5ta. Reunión Binacional Argentino-Chilena sobre Estrategias de Conservación del Huemul, Bariloche, Argentina, pp 30-35

Flueck WT, Smith-Flueck JM (2007) El ciervo rojo exótico en el ambiente patagónico: biología, impacto y opciones de manejo para áreas protegidas. IUCN 2nd Latinamerican Congress on National Parks and Protected areas Bariloche, Argentina

Flueck WT, Smith-Flueck JM, Naumann CM (2003) The current distribution of red deer (Cervus elaphus) in southern Latin America. E J Wildl Res 49:112-119

Forsyth DM (1999) Long-term harvesting and male migration in a New Zealand population of Himalayan tahr Hemitragus jemlahicus. J Appl Ecol 36:351-362

Forsyth DM, Tustin KG (2001) Advances in New Zealand mammalogy 1990-2000: Himalayan tahr. J R Soc NZ 31:251-261

Forsyth DM, Parkes J, Hickling G (2000) A case for multispecies managemt of sympatric herbivore pest impacts in the central Southern Alps, New Zealand. NZ J Ecol 24:97-103

Fraser KW, Cone JM, Whitford EJ (2000) A revision of the established ranges and new populations of 11 introduced ungulate species in New Zealand. J R Soc NZ 30:419-437

Fraser KW, Parkes JP, Thomson C (2003) Management of new deer populations in Northland and Taranaki. Sci Conserv 212:1-30

Godley EJ (1960) The botany of southern Chile in relation to New Zealand and the Subantarctic. Proc R Soc B 152:457-475

Hughey KFD, Hickling GJ (2006) Ecologically based policy evaluation: application to ungulate management in New Zealand. Environ Sci Policy 9:639-651

Jiménez J, Guineo G, Corti P, Smith JM, Flueck WT, Vila A, Gizejewski Z, Gill R, McShea W, Geist V (2008) Hippocamelus bisulcus. IUCN Red List of Threatened Species. IUCN, Gland, Switzerland 
Kittur S, Sathyakumar S, Rawat GS (2009) Assessment of spatial and habitat use overlap between Himalayan tahr and livestock in Kedarnath Wildlife Sanctuary, India. Eur J Wildl Res doi:10.1007/s10344-009-0302-3

Kolar CS, Lodge DM (2001) Progress in invasion biology: predicting invaders. TREE 16:199-204

Nunez MA, Pauchard A (2009) Biological invasions in developing and developed countries: does one model fit all? Biol Invasions doi:10.1007/s10530-009-9517-1

Olson LJ (2006) The economics of terrestrial invasive species: a review of the literature. Agr Resour Econ Rev 35:178194

Perrings C, Dehnen-Schmutz K, Touza J, Williamson M (2005) How to manage biological invasions under globalization. TREE 20:212-215

Petrides GA (1975) The importance of wild ungulates into Latin America, with remarks on their environmental effects. Environ Conserv 2:47-51

Pimentel D, Lach L, Zuniga R, Morrison D (2000) Environmental and economic costs of nonindigenous species in the United States. Bioscience 50:53-65

Richard E, Julia JP (2004) Mamíferos introducidos de Argentina. In: Richard E (ed) Cátedra de Manejo y Conservación de Vida Silvestre, materiales de apoyo docente. Escuela Militar de Ingenieria, La Paz
Sage E (2001) The trouble with tahr. Forest and Bird. (http:// www.forestandbird.org.nz), August

Sala OE, Chapin FS, Armesto JJ, Berlow E, Dirzo J, Bloomfield R et al (2000) Global biodiversity scenarios for the year 2100. Science 287:1770-1774

Simons SA, De Poorter M (2009). Best practices in pre-import risk screening for species of live animals in international trade. In: Proceedings of an expert workshop on preventing biological invasions, University of Notre Dame, IN, USA, 9-11 April 2008. Global Invasive Species Programme, Nairobi, Kenya, pp 1-30

Tustin KG (1990) Himalayan tahr. In: King CM (ed) The handbook of New Zealand Mammals. Oxford University Press, Oxford, pp 392-406

Ubeda C, Grigera D (eds) (1995) Recalificación del estado de conservación de la fauna silvestre Aargentina. Región Patagónica. Secretaría de Recursos Naturales y Ambiente Humano y Consejo Asesor Regional Patagónico de la Fauna Silvestre. Buenos Aires

Vogel CA (1969) Parque Diana. Stefan Schwarz Verlag, München

Williamson M (2006) Explaining and predicting the success of invading species at different stages of invasion. Biol Invasions 8:1561-1568 